\title{
THE DIGITAL WORKSHOP ZONE OF PROXIMAL DEVELOPMENT - STUDENT SHOPPING AMONGST ADVANCED PRODUCTION PROCESSES
}

\author{
Kristin ANDREASSEN, Sigrid HAUGEN and Wenche LYCHE \\ Department of Product Design, Faculty of Technology, Art and Design, Oslo Metropolitan \\ University, Norway
}

\begin{abstract}
How do we train product design students' creative skills using traditional material processing techniques and advanced production processes using Vygotzky's zone of proximal development as a pedagogical tool? Over the years, the Department of Product Design at Oslo Metropolitan University has shifted its curriculum for investigating and processing materials from a focus on traditional analogue craft techniques assisted by digital tools to a focus on digital tools assisted by traditional techniques. The long-standing openness between vast workshop areas at the University creates a landscape of "makerspace shops" for students, meaning that their design ideas can be made into many different product designs and architectural touchdowns. This paper explores how design students in two courses used digital tools and methods in combination with traditional methods and materials. In one course, students explored and innovated new surfaces on textiles for products, art and interiors, using tools and techniques in collaboration with workshop areas other than their own. In the second course, students used 3D printing with clay, while investigating new surfaces, innovative patterns, colour explorations, and form. We found that practical material crossover experiences enhanced creative processes.
\end{abstract}

\section{Keywords: Creative process, material crossover, innovation, digital tools}

\section{INTRODUCTION}

Blended learning spaces are essential for good student experiences [1]. Students and teachers should take risks in design education [2]. In the traditional material printing arts, such textile printing, there is much to learn [3]. Further, these learning environments enhance the zone of proximal development as described by the pedagogical philosopher Vygotsky [4]. In their second semester of study, undergraduates experimented with material surfaces over the course of several weeks. Rewarding risk management during experimentation was an important issue during the course. This opened up a new landscape of innovation, where failure was rewarded as equally as success as long as it was the result of testing a theory methodically. Reflecting upon why the theory failed and suggesting other solutions was an important part of the reward process.

\subsection{Experimenting with material surfaces using digital and traditional analogue craft tools}

The well-equipped workshops at the Department of Product Design allowed a wide range of possibilities for working with materials, including glass, wood, metal, concrete, textiles, ceramic and polymers. Skilled tutors were present in each material area on an everyday basis. All students attended basic training in health, security and environment, material knowledge and how to process materials in all areas. Furthermore, students were offered specialised training in material areas of their choice. The health, security and environment certification allowed students to work independently and to explore the facilities and possibilities of the workshops even when tutors or technical staff were not present. Being able to work freely with different materials affected the creative process in a positive way. Students developed a fairly high level of independence in their workflow rapidly, because tutors did not control the direction of their design process, their choice of materials or their choice of processing techniques. 


\section{METHODS}

The case study method was chosen for this study, because it allowed us to study the research question in a real-life context [5]. In total, 43 students were asked to choose their focus from different material areas. Then, the class divided into "material groups" and were guided through the process of investigation by specialised tutors. During the first semester, they attended a certification course in all material areas and an introduction to and training in 3D drawing programmes, such as Fusion 360. In the second semester, their challenge was to achieve further and more specialised material knowledge and knowledge on how to process materials, including the crossover use of materials, processing methods and tools. Teaching student's 3D drawing skills in the first semester instead of the second was a shift in the curriculum from previous years, which enabled this group of students to operate digital tools, such as those used for additive manufacturing. As a creative method and a way of thinking, crossdisciplinary material and design studies is a strong tool for escaping conformist way of approaching design challenges.

\subsection{Experiments in textile workshops}

The experiments explored how to obtain and generate new and innovative surfaces on textiles through the use of analogue methods to provoke and challenge textiles and alter fabric behaviour and look. The task in the workshop had its starting point in textiles, introducing students to various textiles and challenging them to explore new surfaces for product design development. The goal was to push innovation skills and ask students to think outside the box and use all their competence and creativity in developing new textile surfaces for interior products and exterior products. Students created 2D and 3D surfaces from flat textiles using analogue methods, such as stitching, burning, handcrafting and digital tools, such as Illustrator, Photoshop, digital textile printers, 3D printers and laser cutters. Fabrics that were given to students were silk and nylon organza, jersey, tulle and leather. Digital printers create new surfaces on textiles, meaning students can reach out to clients with their new designs, such as chairs, lampshades and room dividers or even public spaces. Students may increase their personal expression in design through their exploration of surfaces and make products for sale quickly using digital tools. Understanding surfaces is about seeing possibilities for new design discussing if the same surface design can be used on different products. Surface design is also applicable for wood, metal and ceramics, inspiring students to cross over in workshops to obtain new product developments. Burning fabrics, as a method in creativity, destroys surfaces and open up new surface aesthetics.

\subsection{Experiments in ceramic workshops}

In the ceramic workshop, students were introduced to the possibilities of 3D-printing using the robotised clay extrusion method. Commercialised equipment for this technique is fairly new and the processing methods are still in their early stages of exploration worldwide. It is possible to get an overview of much of what is going on in the field right now via the internet. Our research group also contacted several similar research groups at other universities.

\section{ANALOGUE AND DIGITAL SURFACE EXPERIMENTS}

With different levels of supervision, both voluntary and mandatory, students achieved different levels of result based on the scaffolding available for learning, as described in Vygotsky's concept, the ZPD [4]. This study deepened our understanding of the ZPD in a specific context.

\subsection{Case Study 1: Surface design in the textile workshop}

In this 2-day workshop, first year undergraduate students learned about the features and character of given textiles, such as their flow, weight, softness/hardness, how the fabrics would normally be used and their fibre composition. As students had already been introduced to Illustrator, Photoshop, laser cutting and 3D printing, they could immediately start exploring new surfaces by creating a report for print. They repeated prints in quadratic patterns and developed prints for canvas fabric that could be digitally printed.

We believe that printing on fabrics is a great tool in product design development, because it gives students a new possibility for customising the aesthetic surfaces of their products. One student wished to destroy the beauty of silk organza and change its performance to achieve a new surface. She interrupted the weaving by stretching the silk, which was composed of two colours and created a new landscape with a 3D effect. She had no idea what to use it for, but tutors reminded her of her repeat 
pattern knowledge, and she proceeded with Photoshop, manipulating the pattern for digital printing on canvas.

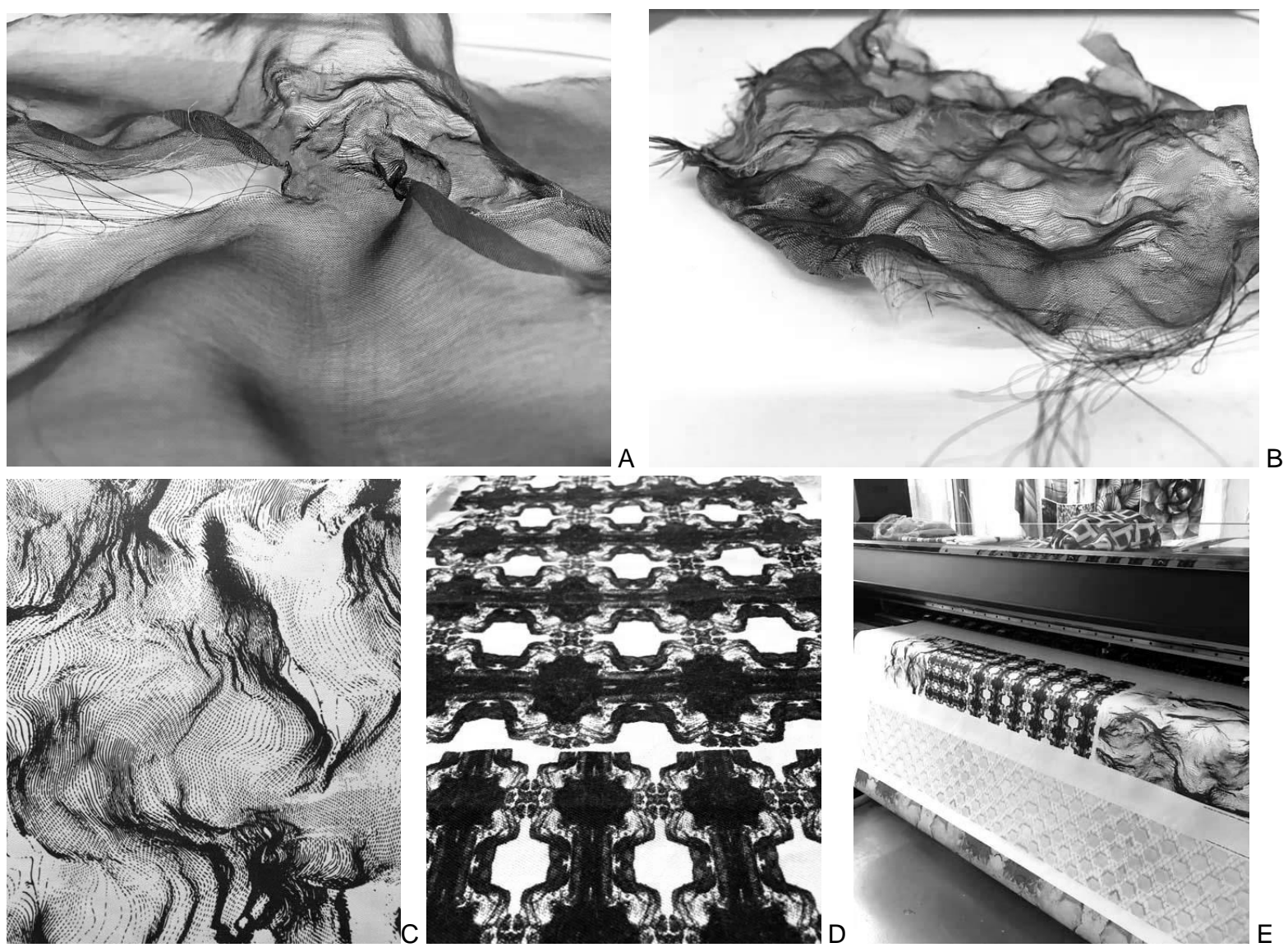

Figure 1. A. Silk organza B. 3D manipulation C. Photoshop image D. Canvas print E. The digital textile printer

Some of the students used a handheld gas burner and burnt all textiles one by one, while others piled them on top of each other before burning with the gas torch to achieve unexpected outcomes.

Fabric exposed to heat reacted according to the speed and strength of the burner and gave results beyond belief. Students found an element for pattern making and made this into a repeated pattern for printing using Illustrator.
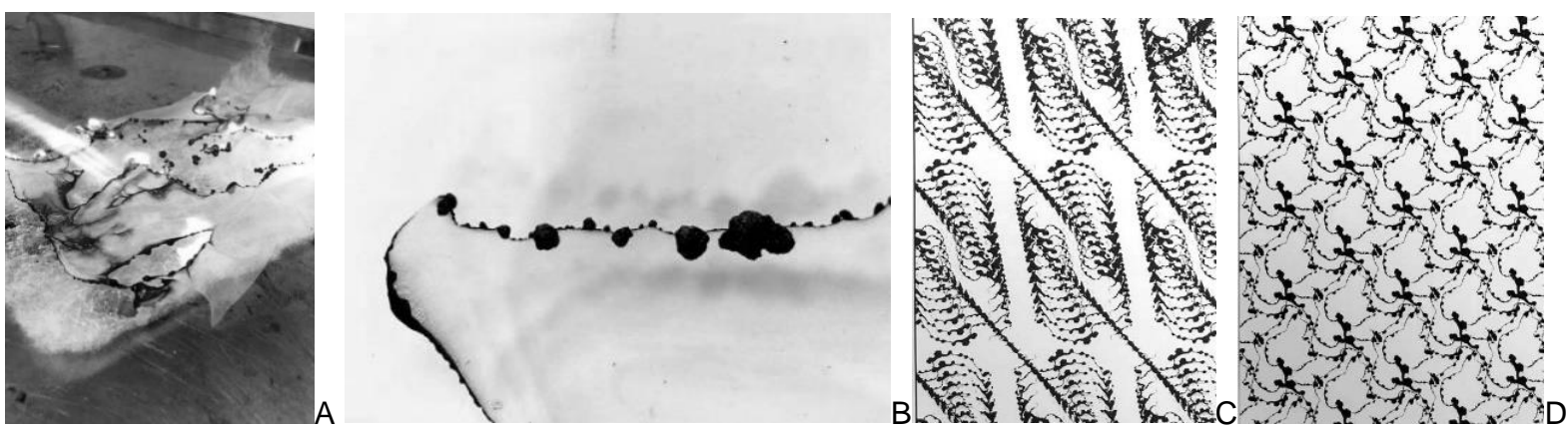

Figure 2. A. Burnt organza B. Chosen piece C. Photoshop image D. Repeated surface pattern ready for print

One student 3D printed on textiles, creating a new surface by connecting layers of fabric into the printer, stopping the 3D print and adding a new layer of fabric. In this way, the student discovered a joint method for textiles. 3D printing on textiles gives strength to textiles without losing their flow and softness. 

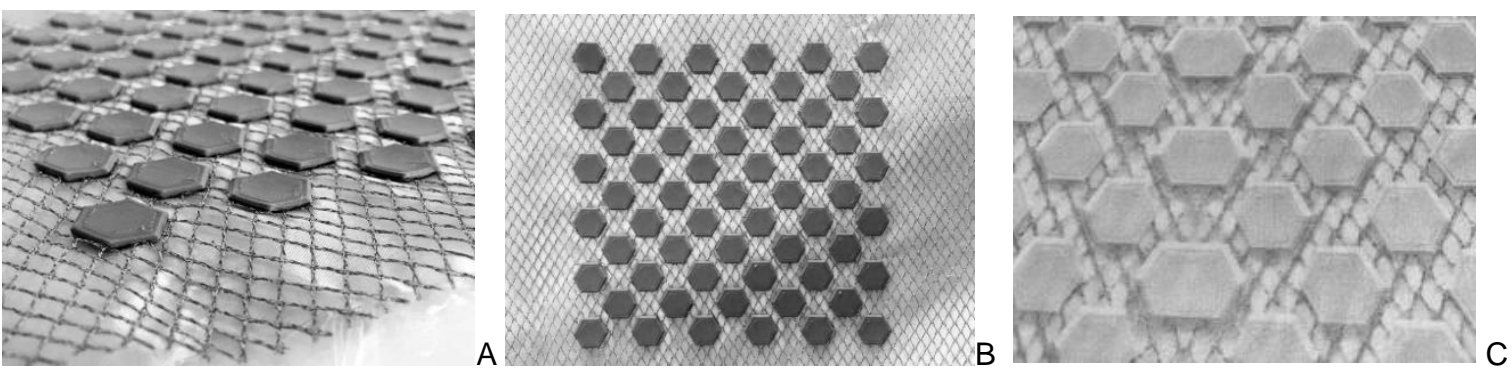

Figure 3. A. 3D printed polymer on fabrics $B .3 D$ printed polymer report on silk lining $C$. Acrylic tulle, textile printed pattern on canvas

Students were asked the following questions about surface design and textiles learning outcomes after the workshop:

\subsubsection{How do you think differently about surface design now, compared to before the course?}

Student A: - I did not realise that the variety of textiles could give endless possibilities. It is important to explore to understand the performance of fabrics.

Student B: - I have learned that the result you get is not the product but part of a process. The creation of an expression is just part of a bigger picture.

3.1.3 How has alternating between analogue and digital methods affected your creative process? Student A: - I have learnt a lot. The digital world opens up many ideas and is very fast; I enjoy that. I get impatient and love efficiency, so I like seeing results quite fast. It is much more fun too.

Student B: - I work step by step, looking at the results and then I consider and evaluate my design process.

\subsubsection{How has engaging in textiles developed your aesthetic taste?}

Student A: - I do not want to stick to one style and aesthetic, but I like the variations textiles give.

Student B: - I want to make my work more elegant, and I want to work on a larger scale, but it is limited by the printers and tools I use.

\subsubsection{In what way did you develop your material understanding using digital tools?}

Student A: - I have learned to experiment with textiles, and I now know textiles can be so much more. That is, I can take a photo of a textile, insert it to Photoshop to add contrast and then make a repeat pattern.

Student B: - I have discovered that identical fabrics with different fibre contents are more or less suitable for 3D polymer printing. Some work, others don't.

\subsection{Experimenting with robotised clay extrusion}

Students were guided in installing software for different printers. They learned the different aspects of preparing clay and how to add colour and other additives to the material. In the first days, they were guided on the printing process. To be able to work on their own, they needed to learn how to fill the clay tubes and adjust the flow, speed and air pressure. They were also shown different ways to experiment with this kind of equipment. Students were introduced to using and maintaining different printers.

As the techniques contain so many variables, it was essential to establish a technical knowledge base for the students. Thereby, they could practice their new knowledges and help each other before moving on to a level of experimentation. Web resources and social media have good information on what is being done with clay printers elsewhere, and a lot of sharing took place. Two students were asked a number of questions about their experiences through the subject, including the following:

\subsubsection{How do you think differently about design now compared to before the process?}

Student C: - When I first saw the printer, I thought, 'I am not a technical girl'. But then I thought, 'Why can I not become one?' After I learned Computer Assisted Drawing (CAD) and how to use the settings on the 3D printer, I discovered a new innovation landscape with many possibilities for my design ideas. Student D: - The process of printing may add an interesting surface or form to a simple cylinder shape. Getting good results is time consuming, and it is important to spend time. 


\subsubsection{How has alternating between analogue and digital methods affected your creative process?}

Student C: - I like to combine physical sketches and CAD drawings in the computer. In my creative process, it has been helpful to draw my ideas in Fusion 360, so I can turn them around and see them from different angles. If I feel the need to have a physical model, then I can make a mock-up. But it is so much easier to make it in the CAD programme. It has been very positive for me to be able to change perspectives and alternate between the two.

Student D: - I enjoy working with my hands, but I knew I had to improve my digital skills. Printing with clay was a huge inspiration to get better at CAD drawing. This course motivated me to make drawings, so I could print and design objects. I learned a lot about materials and techniques and used online resources. I learned the importance of actively approaching tutors for advice and tips to get on with the process.
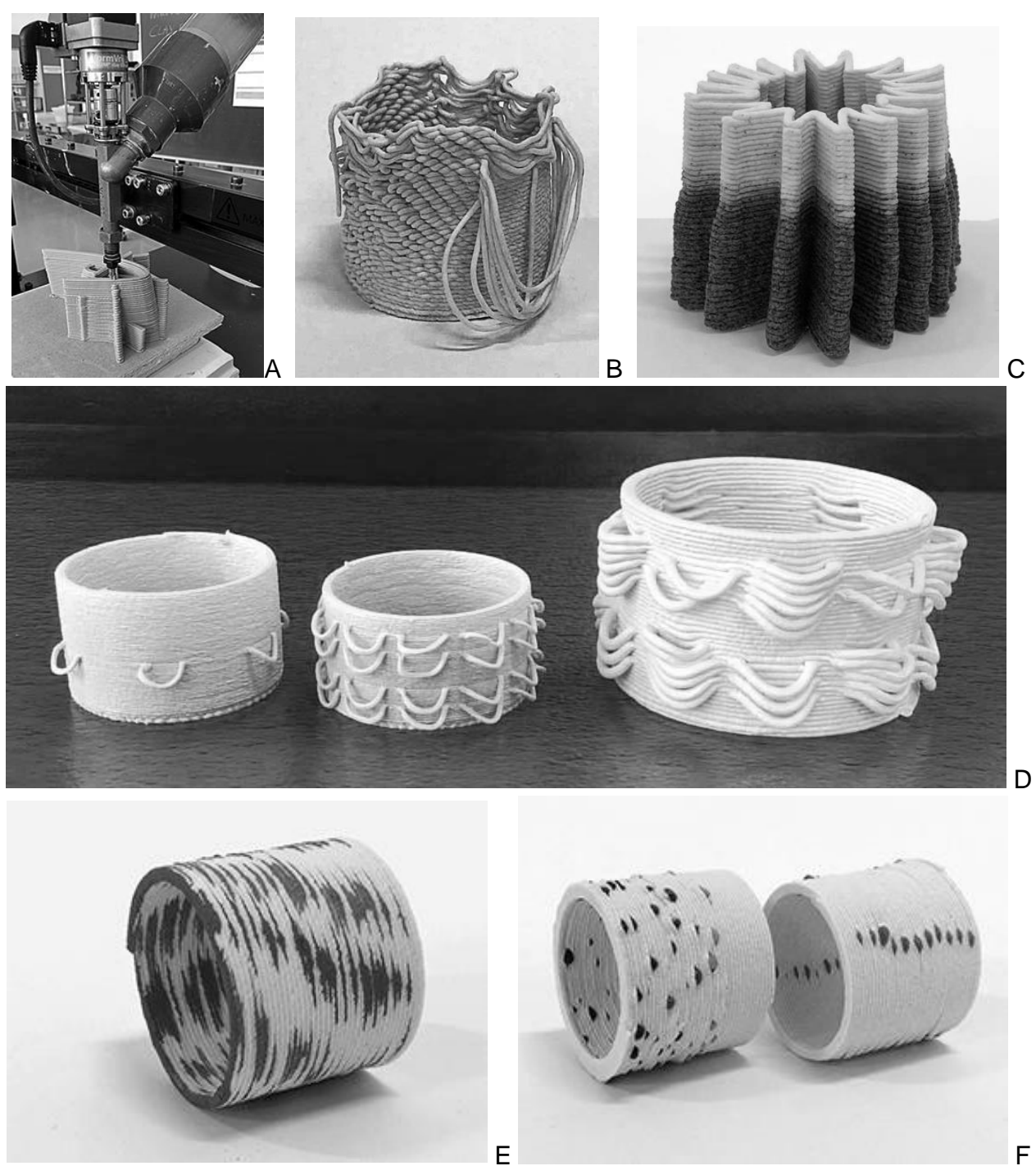

Figure 4. A. Clay printer B-F. Tests on form, pattern and additives

\subsubsection{How has material and process affected your creativity?}

Student C: - Clay printing has its limitations. Clay is soft, and because of gravity, it is difficult to print angles above 40 degrees. Therefore, I cannot make very complex forms. But the hands are very good tools, and handmade parts may be integrated or used as a support during printing. A wet brush is always a good help.

Student D: - Colour, movement and flexibility has inspired me. I wanted to add pattern and colour. CAD drawing and the digital part were not as inspiring. Practice made it easier. 


\subsubsection{How has the work with the clay printer affected the aesthetic expression of your work?}

Student C: - It has given me so many possibilities. The printer gives an expression itself because of the horizontal stripes that come from the technique. It fits my own expression, which I would call playful and timeless. Clay printing has helped me make physical objects of ideas that previously only existed on paper. I am eager to learn more. I will also keep using analogue methods.

Student D: - It has made me challenge my aesthetic expression. If the file is perfect, then the print will come out as you have drawn it. Now, I will take it to the next step.

\subsubsection{In what ways have you developed your understanding of material through the use of digital techniques?}

Student C: - One of the things I have learned is the importance of clay viscosity. The softness of clay is important to make it printable. I have experimented combining clay with other materials and printing it. The result was, for me, a "new" material that resembled granite stone (Fig 4C.)

Student D: - I have learned that the condition of the material is crucial for a successful print. Even if the file is perfect, the print may fail because of air bubbles, poor viscosity or rough particles in the clay. I also consider the cost of materials and the importance of the maintenance of the machine.

\section{DISCUSSION - CREATIVE PROCESS, MATERIAL CROSSOVER AND INNOVATION}

In the theory of Zone of Proximal Development Vygotskij problematize how learning is related to tutoring. In this case, undergraduates took advantage of tutors' guidance on how to develop their ideas by practicing creative processes through workshop practice. The ZPD suggests that individually adjusted tutoring enhance learning. As tutors, it is crucial for students' development that we see when they are ready for the next challenge, such as in this study where burning and disrupting the weave structure of textiles might seem extreme, but it is also cathartic and fun, not pretentious or ambitious If the challenge does not come, the speed of learning slows down [4]. Some students tend to dwell in the comfort zone of familiar working processes. Being challenged may be uncomfortable but can be necessary to improve skills. They need individual guidance to discover new possibilities. Explorative processes improve students' own strength, independence and understanding of how to use creative tools. In conclusion to the study it seems that many students benefitted from changing their focus between working with crafting techniques and digital tools in a blended learning space. Students experimented with material combinations and discovered new aesthetic material qualities. Tutors guided students by suggesting interesting areas of experimentation. As students were already trained in the different material workshops, they could experiment with innovative material combinations. The combination of porcelain and glass powder in the clay printer and the printed polymer on textile are good examples (Fig. $3 \mathrm{~A}, \mathrm{~B}$ and 4 C, F). Exposing students to such new ways of working and forcing them to engage in explorative design processes without knowing where it would lead challenged most students in a good way in this study.

\section{REFERENCES}

[1] Milne A.J. Designing blended learning space to the student experience, Educase, 2006

[2] Arthur L. and Masrch P. Stop Playing it Safe: The Importance of Taking a Risk in Design Education, 2016 (Papeorg).

[3] Jackson P. How to make repeat pattern: A Guide for Designers, Architects and Artists, 2018 (Laurence King Publishing, London).

[4] Vygotskij L.S., John-Steiner V. and Cole M. Mind in Society:

The Development of Higher Psychological Processes

[5] Yin R.K. Case Study Research: Design and Methods, 2009 (Sage, Thousand Oaks). 